\title{
Expanding the Chemical Diversity of the Antitumoral Compound Mithramycin by Combinatorial Biosynthesis and Biocatalysis: The Quest for Mithralogs with Improved Therapeutic Window
}

Authors

Affiliations
Carmen Méndez ${ }^{1}$, Javier González-Sabín ${ }^{2}$, Francisco Morís², José A. Salas ${ }^{1}$

${ }^{1}$ Departamento de Biología Funcional e Instituto Universitario de Oncología del Principado de Asturias (I.U. O. P.A), Universidad de Oviedo, Oviedo, Spain

${ }^{2}$ EntreChem S. L., Edificio Científico Tecnológico, Campus El Cristo, Oviedo, Spain
Key words

- Streptomyces argillaceus

- Streptomycetaceae

- mithramycin

- combinatorial biosynthesis

- biocatalysis

- aureolic acid

- mithralog received Nov. 18, 2014 revised June 16, 2015 accepted July 22, 2015

Bibliography

DOI http://dx.doi.org/

$10.1055 / \mathrm{s}-0035-1557876$

Published online September 21, 2015

Planta Med 2015; 81:

1326-1338 @ Georg Thieme Verlag KG Stuttgart · New York . ISSN 0032-0943

\section{Correspondence}

José A. Salas

Departamento de Biología Funcional e Instituto Universitario

de Oncología del Principado de Asturias (I.U. O.P.A)

Facultad de Medicina

Universidad de Oviedo

c/Julián Clavería s/n

33006 Oviedo

Spain

Phone: + 34985103652

Fax: + 34985103534

jasalas@uniovi.es

\section{Abstract \\ $\nabla$}

Mithramycin is an antitumor compound of the aureolic acid family produced by Streptomyces argillaceus. It has been used to treat several types of cancer including testicular carcinoma, chronic and acute myeloid leukemia as well as hypercalcemias and Paget's disease. Although the use of mithramycin in humans has been limited because its side effects, in recent years a renewed interest has arisen since new uses and activities have been ascribed to it. Chemically, mithramycin is characterized by a tricyclic aglycone bearing two aliphatic side chains attached at $\mathrm{C} 3$ and $\mathrm{C}$, and disaccharide and trisaccharide units attached at positions 2 and 6 , respectively. The mithramycin gene cluster has been characterized. This has allowed for the development of several mithramycin analogs ("mithralogs") by combinatorial biosynthesis and/or biocatalysis. The combinatorial biosynthesis strategies include gene inactivation and/or the use of sugar biosynthesis plasmids for sugar modification. In addition, lipase-based biocatalysis enabled selective modifications of the hydroxyl groups, providing further mithramycin analogs. As a result, new mithramycin analogs with higher antitumor activity and/or less toxicity

\section{Introduction}

$\nabla$

MTM is an antitumor compound of the aureolic acid family produced, among other bacteria, by Streptomyces argillaceus. It has been used to treat several types of cancer in the 1970 s, and later, hypercalcemias and Paget's disease until its discontinuation at the turn of the 21st century. Although the use of MTM in humans has been limited because of the lack of a therapeutic window, recent literature evidence linking its mechanism of action to both antitumoral and other therapeutic activities has fueled a renewed interest in this have been generated. One, demycarosyl-3D- $\beta$-Ddigitoxosyl-mithramycin SK (EC-8042), is being tested in regulatory preclinical assays, representing an opportunity to open the therapeutic window of this promising molecular scaffold.

\section{Abbreviations}

$\nabla$

CNS: $\quad$ central nervous system

DIG-MTM-SK: demycarosyl-3D- $\beta$-D-digitoxosylMTM-SK

EWS-Fli1: Ewing sarcoma-Fli1 fusion gene

FIH: first-in-human (clinical trials)

GIST: gastrointestinal tumors

NSCLC: non-small cell lung carcinoma

MTM: mithramycin

MTM-SA: mithramycin short side chain acid

MTM-SDK: mithramycin short side chain

diketone

MTM-SK: mithramycin short side chain ketone

NCI: $\quad$ National Cancer Institute

NDP: $\quad$ nucleotide diphosphate

PK: pharmacokinetic

TDP: $\quad$ thymidine diphosphate

privileged natural scaffold. The growing body of literature on MTM (more than 400 PubMed-indexed articles since 2000 only) showing promising biological activity, especially in oncology [1], reflects the potential of this molecular class for the treatment of different types of cancer. This trend is crowned by two recent MTM clinical trials sponsored by the $\mathrm{NCI}$ in two unrelated indications: Ewing sarcoma (NCT01610570) and NSCLC (NCT01624090), which address two different targets in each histology (EWS-FLI fusion gene in sarcoma [2] and ABCG2 transporter in lung cancer [3]). More recently, the potential of MTM for can- 




Fig. 1 Genetic organization (A) and biosynthesis pathway (B) of mithramycin in S. argillaceus. 1 MTM; 2 4-demethylpremithramycinone; 3 premithramycinone; 4 premithramycin A1; 5 9-demethyl-premithramycin A2; 6 9-demethyl-premithramycin A3; 9 premithramycin $A 3$; 12 3A-deolivosylpremithramycin B; 13 premithramycin B. cers depending on constitutively activated targets, for example, GIST, a gastrointestinal tumor that depends on the continuous expression of the oncogenic c-kit kinase, has been reported using an unbiased compound screening [4]. Also, it has been found that MTM targets the chemotherapy resistant SOX2+ cell population in the sonic hedgehog subgroup medulloblastoma. Evidence of the ability of the molecule to target propagating tumor subpopulations (cancer stem cells) represents yet another high-profile example of MTM as a potential anticancer drug [5].

Despite the promising biological activity of MTM, which is generally related to its ability to modulate transcription, especially genes regulated by the $\mathrm{Sp} 1$ transcription factor, the drug industry still regards Sp1 as an undruggable target, at least by the drug discovery approaches currently in place. Aside from the (mostly distant) clinical experience with MTM, there has been only one attempt at the development of a Sp1-targeted drug, named terameprocol, whose development apparently stopped in 2007 after the sponsor completed FIH phase I clinical trials [6]. All these facts have stimulated an interest in MTM analogs (mithralogs) with improved properties, with a focus on those with lower toxicity, thus having better clinical chances than the parental natural product.
This review describes the results of the efforts to expand the chemical space of MTM and the biological properties of the analogs generated in a quest to identify a viable candidate for clinical development. Chemically, MTM ( Fig. 1 B) is characterized by an aglycone with three rings and two side chains, which is glycosylated by a disaccharide and a trisaccharide chain. The MTM gene cluster has been cloned and characterized, and the biosynthesis pathway has been established. This has allowed the development of several MTM analogs by combinatorial biosynthesis and/or biocatalysis. Different strategies of combinatorial biosynthesis have been used to generate new MTM derivatives, including gene inactivation, gene expression, the use of sugar biosynthesis plasmids for sugar modification, and combinations of both approaches. In addition, biocatalysis has been used to further diversify the MTM scaffold. Since MTM is a polyhydroxylated molecule, the use of hydrolases, especially lipases, to selectively modify some of the hydroxy groups is a suitable approach to expand the chemical space both from the wild-type product and the combinatorial biosynthesis analogs.

As a result of all these strategies, new mithralogs with higher antitumor activity and/or less toxicity have been generated, and the efficacy of the selected analogs has been tested in murine models of human cancer. DIG-MTM-SK (EC-8042) is the lead can- 


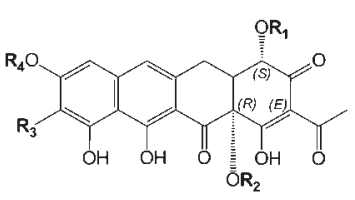

$$
\begin{aligned}
& 2 R_{1}=H \quad R_{2}= \\
& \text { H } \\
& 3 \mathbf{R}_{\mathbf{1}}=\mathrm{CH}_{3} \quad \mathbf{R}_{\mathbf{2}}= \\
& 4 \mathbf{R} 1=\mathrm{CH}_{3} \quad \mathbf{R}_{\mathbf{2}}= \\
& \mathbf{5} \mathbf{R}_{\mathbf{1}}=\mathrm{CH}_{3} \quad \mathbf{R}_{\mathbf{2}}= \\
& \text { OH } \\
& \mathbf{R}_{\mathbf{3}}=\mathrm{H} \quad \mathbf{R}_{\mathbf{4}}= \\
& \begin{array}{ll}
8 \mathbf{R}_{\mathbf{1}}=\mathrm{CH}_{3} & \mathbf{R}_{\mathbf{2}}= \\
9 \mathbf{R}_{\mathbf{1}}=\mathrm{CH}_{3} & \mathbf{R}_{\mathbf{2}}= \\
10 \mathbf{R}_{\mathbf{1}}=\mathrm{CH}_{3} & \mathbf{R}_{\mathbf{2}}=
\end{array} \\
& 11 \mathbf{R}_{\mathbf{1}}=\mathrm{CH}_{3} \quad \mathbf{R}_{\mathbf{2}}=
\end{aligned}
$$
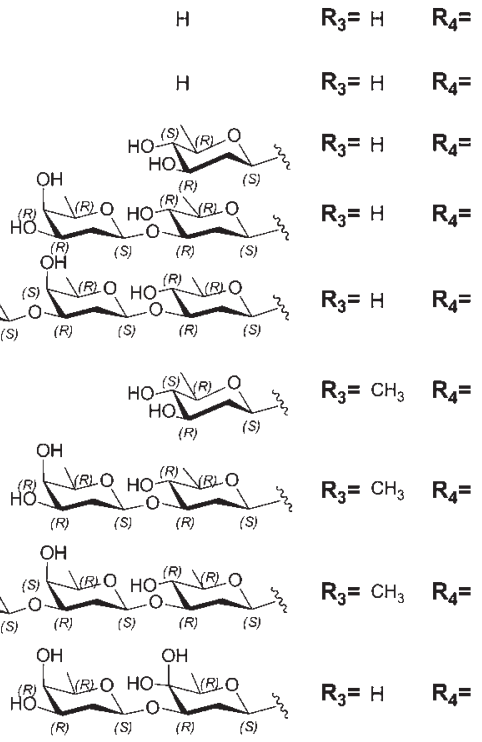

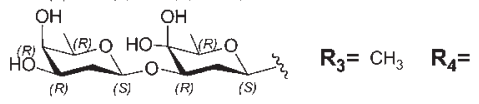

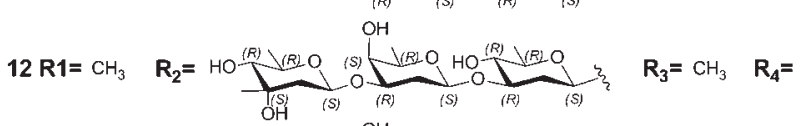

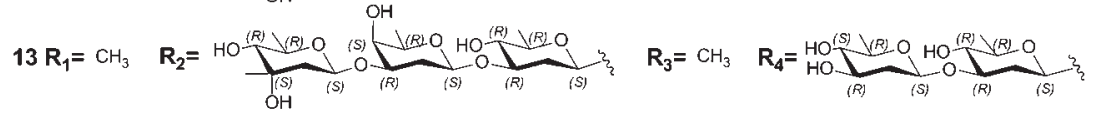

$$
\begin{aligned}
& \text { (1) }
\end{aligned}
$$

Fig. 2 MTM derivatives generated by gene inactivation: tetracyclic compounds. 2 4-Demethylpremithramycinone; 3 premithramycinone; 4 premithramycin A1; 5 9-demethyl-premithramycin A2; 6 9-demethyl-premithramycin A3; 7 9-C-methylpremithramycin A1; 8 premithramycin A2; 9 premithramycin A3; 10 4;A-keto-9-demethylpremithramycin A2; 11 4A-ketopremithramycin A2; 12 3A-deolivosylpremithramycin B; 13 premithramycin $B ; 14$ premithramycinone $G$.

\section{Mithramycin Gene Cluster and Biosynthesis Pathway in Streptomyces argillaceus \\ $\nabla$}

The aim of combinatorial biosynthesis is to produce novel compounds by generating recombinant microorganisms containing combinations of biosynthesis genes that are not found in nature. The use of combinatorial biosynthesis requires knowledge of both the gene cluster and the pathway for the biosynthesis of the target compound. The MTM gene cluster of S. argillaceus ATCC 12956 has been cloned and characterized [8]. It comprises 34 genes and is flanked by two repeated DNA sequences of 241bp [9] ( Fig. 1A). Functions to these genes were assigned by comparing their gene products with similar proteins in databases, generating mutants by targeted gene inactivation, expres- sion of sets of genes, and/or in vitro assays of the corresponding enzymes [8]. The pathway for MTM ( $\odot$ Fig. 1 B) starts by the condensation of ten malonyl-CoA units by the type II polyketide synthase MtmPKS to render a 20-carbon chain that undergoes regioselective cyclizations by aromatase MtmQ and cyclases MtmX and MtmY, oxygenation by MtmOII, and reductions to form the first isolable intermediate $\mathbf{2}$ [10-13]. Then, $\mathbf{2}$ is converted into $\mathbf{3}$ by $O$-methylase MtmMI [14], and in turn is sequentially glycosylated by glycosyltransferases MtmGIV, MtmGIII, and MtmGIV to render $\mathbf{6}$, which contains a trisaccharide of D-olivose-D-olioseD-mycarose incorporated at position C12a-O [15,16]. This compound is $C$-methylated at the C9 position by methylase MtmMII $[14,17]$, and further glycosylated with two D-olivoses by the action of glycosyltransferases MtmGII and MtmGI to render 13 [18, 19]. Then, the oxygenase MtmOIV opens the fourth ring via a Baeyer-Villiger reaction to generate MTM's characteristic tricyclic aglycone with a 5-carbon side chain [20-22]. This oxygenase plays a key role in the biosynthesis of MTM since it converts biologically inactive tetracyclic intermediate into active tricyclic MTM. Finally, the highly functionalized pentyl side chain generated after MtmOIV is reduced by ketoreductase MtmW to render 


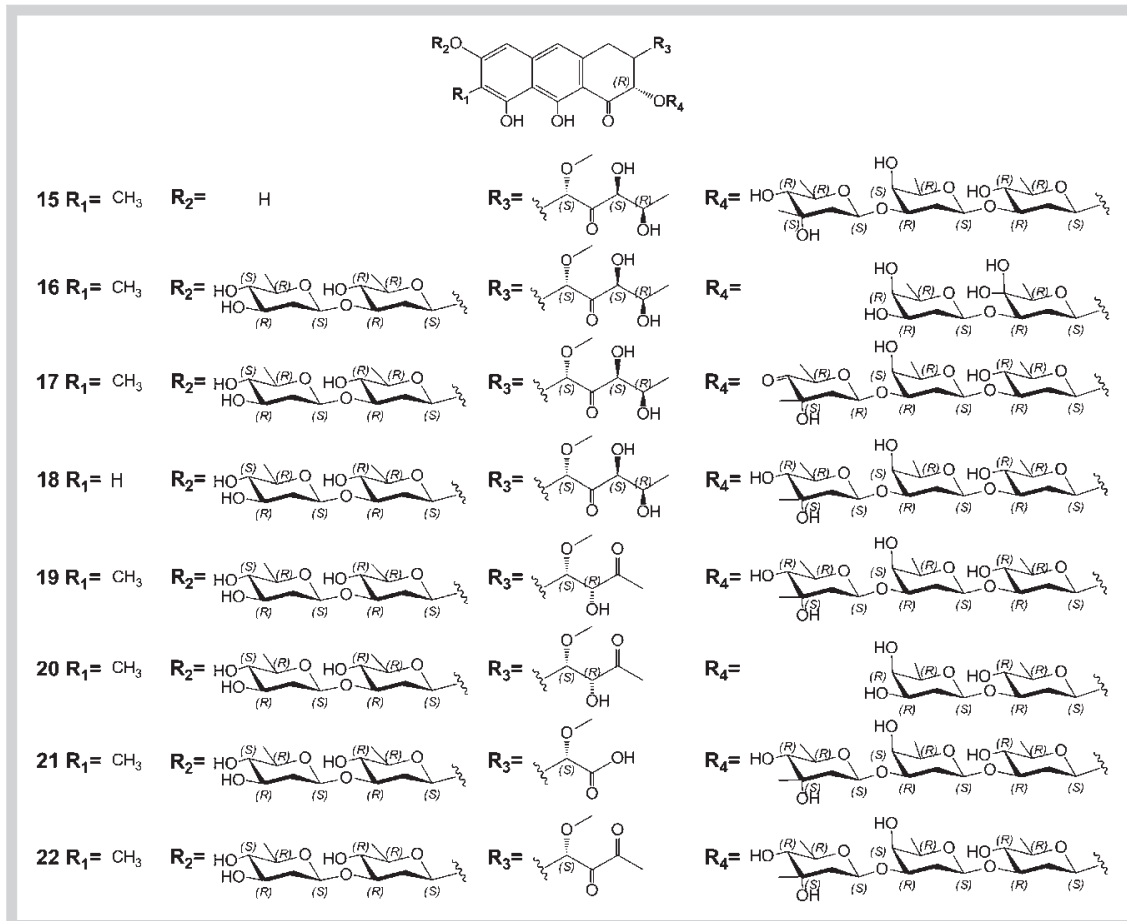

Fig. 3 MTM derivatives generated by gene inactivation: tricyclic compounds. 15 Premithramycin $\mathrm{A} 4$; 16 4C-keto-demycarosyl-MTM; 17 4E-keto-MTM; 18 7-demethyl-MTM; 19 MTM-SK; 20 demycarosylMTM-SK; 21 MTM-SA; 22 MTM-SDK. the final compound MTM [23], which is secreted outside the cell by the ABC transporter MtrAB [24].

\section{Mithramycin Analogs by Gene Inactivation \\ $\nabla$}

Several strategies of combinatorial biosynthesis can be used to generate new derivatives of a target compound. One of these strategies is gene inactivation [25]. By generating mutants in $\mathrm{mtm}$ genes (mtmMI, mtmMII, mtmD, mtmU, mtmC, mtmTIII, mtmGIII, mtmGII, mtmGI, mtmoII, mtmOIV, mtmW), several new compounds were identified that showed either a tetracyclic ( $\bullet$ Fig. 2) or a tricyclic core structure ( $\bullet$ Fig. 3). Bioassays of these compounds established the first structure-activity relationships for mithralogs. That pointed out that antitumor activity required glycosylated derivatives to contain both a tricyclic core and a methyl group at the $\mathrm{C} 7$ position. Some of these compounds showed high antitumor activity. Thus, by inactivating $\mathrm{mtmC}$ that codes for an enzyme that catalyzes the 4-ketoreduction and the C3-methyl transfer reactions during the biosynthesis of TDP-Dolivose and TDP-D-mycarose, respectively $[16,26]$, three new compounds were generated (10 and $\mathbf{1 1}$ in OFig. 2; 16 in - Fig. 3), all lacking D-mycarose and containing an unreduced C4 carbonyl group at the D-olivose of the trisaccharide [27]. Compound 16 ( $\odot$ Fig. 3) showed antitumor activity against human tumor cell lines of lung and breast cancer. Moreover, by inactivating the ketoreductase gene $\mathrm{mtmW}$ responsible for reducing the 3carbon side chain, four new compounds were generated (19-22, - Fig. 3), all containing unreduced and shorter carbon side chains $[23,28]$. All four compounds showed high antitumor activity, with 19 (MTM-SK) (up to 9 times higher than MTM, particularly against melanoma, leukemia, ovarian, and CNS cancer cells) and 22 (MTM-SDK) (up to 2 times higher than MTM and MTM-SK against several ovarian cancer cell lines) $[23,28]$ being the most active ones.

\section{Generation of Mithramycin Derivatives by Modifying the Tricyclic Core of the Aglycone by Gene Expression \\ $\nabla$}

Another strategy for combinatorial biosynthesis is the use of genes from pathways involved in the biosynthesis of structurally related compounds. The tetracyclic aglycone of MTM (premithramycinone) structurally resembles that of antitumorals nogalamycin and tetracenomycin C. By introducing a plasmid containing genes for nogalamycin aglycone (including the ketoreductase snoaD and the aromatase snoaE) into $S$. argillaceus, four new compounds were generated lacking the C8 hydroxyl group and consequently the disaccharide chain (compounds 23 to 26 in O Fig. 4A) [29]. On the other hand, by expressing the oxygenase $\mathrm{tcmH}$ from the tetracenomycin gene cluster in the mutant strain S. argillaceus M7O2 (lacking oxygenase mtmOII) [12], the new hybrid compound 27 (O Fig. 4B) was generated [30]. This compound showed changes in the structure of the aglycone that prevented its further glycosylation, however, it showed anticancer activity in the same range as MTM against tumor cell lines of squamous cell carcinoma, melanoma, NSCLC, and breast carcinoma [30].

\section{Generation of Mithramycin Derivatives with Altered Glycosylation Profile \\ $\nabla$}

As mentioned above, MTM is a glycosylated compound with an upper disaccharide chain of D-olivose-D-olivose, and a lower trisaccharide chain of D-olivose-D-oliose-D-mycarose. All these sugars are 2,6-deoxyhexoses synthesized from glucose-1-phosphate through four common enzymatic steps to give rise to the intermediate NDP-4-keto-2,6-dideoxy-D-glucose, which is further methylated and/or reduced to render the final activated deoxysugars that are substrates for glycosyltransferases [16,26,31]. Gene inactivation experiments of genes involved in the biosynthesis of MTM sugars (mtmD, mtmU, mtmV, mtmC, and mtmTIII) 



or in their transfer to the aglycone (mtmGI, mtmGII, mtmGIII, and mtmGIV) indicated that these sugars are key for antitumoral activity $[15,18,26,27]$. Therefore, several attempts were carried out in order to modify the glycosylation pattern of MTM to generate new potentially bioactive derivatives.

Urdamycin A is a glycosylated angucycline polyketide produced by Streptomyces fradiae TÜ2717 that contains the D-olivose-Lrhodinose-D-olivose trisaccharide linked by a $C$-glycosidic bond to the aglycone, which resembles, to some extent, MTM intermediates $\mathbf{2}$ and $\mathbf{3}$ ( $\bullet$ Fig. 2). By expressing glycosyltransferase UrdGT2 that catalyzes the $C$-glycosylation of the urdamycin aglycone [32] in mutants S. argillaceus M3G4 (a mtmGIV-minus mutant, blocked at the first glycosylation step of MTM [15]) and $S$. argillaceus M3 $\triangle \mathrm{MG}$ (lacking all glycosyltransferases, mtmGI-IV, and methylases mtmMI and MtmMII [20]), four novel C-glycosylated compounds were generated (28-31, $\odot$ Fig. 5) that contained a D-olivosyl or a D-mycarosyl residue attached through a C-glycosidic bond to either 2 or $\mathbf{3}$ [33]. In addition, the co-expression of glycosyltransferases UrdGT2 and LanGT1 (the last from the angucycline landomycin gene cluster of Streptomyces cyanogenus S136 [34]) in S. argillaceus M3G4 resulted in the formation of the novel derivative 32 ( Fig. 5) with the D-olivose-D-olivose disaccharide attached by a $C$-glycosidic bond to the aglycone [33].
On the other hand, new mithralogs with different glycosylation profiles were generated by endowing the producer strain with the capability to synthesize new sugars. To achieve this aim, several "sugar plasmids" coding for the biosynthesis of different NDP-deoxysugars were constructed (L-rhamnose, D- or L-olivose, D-oliose, D- or L-digitoxose, D-boivinose, D- or L-amicetose, L-rhodinose, L-mycarose, and L-chromose B) [35-38]. By individually introducing these plasmids into the $S$. argillaceus wild-type strain, $S$. argillaceus M7U1 (blocked in the biosynthesis of D-olivose [26]), or S. argillaceus M7C1 (blocked in D-mycarose biosynthesis [26]), 15 new compounds were generated (33-47, o Fig. 6) differing from MTM in the glycosylation pattern [7,39,40]. Most of the compounds reflected high antitumor activity at micromolar concentrations against a panel of three tumor cell lines, with 33,35 , and 36 being the most active ones $[39,40]$. Moreover, an apoptosis TUNEL assay revealed that $\mathbf{3 3}$ and $\mathbf{3 5}$ showed improved activity against the estrogen receptor (ER)-positive human breast cancer cell line MCF-7 compared with the parent drug MTM. In addition, $\mathbf{3 3}$ and $\mathbf{3 6}$ showed significant effects on the ER-negative human breast cancer cell line MDA-MB-231, which is not inhibited by the parent drug MTM [39]. 


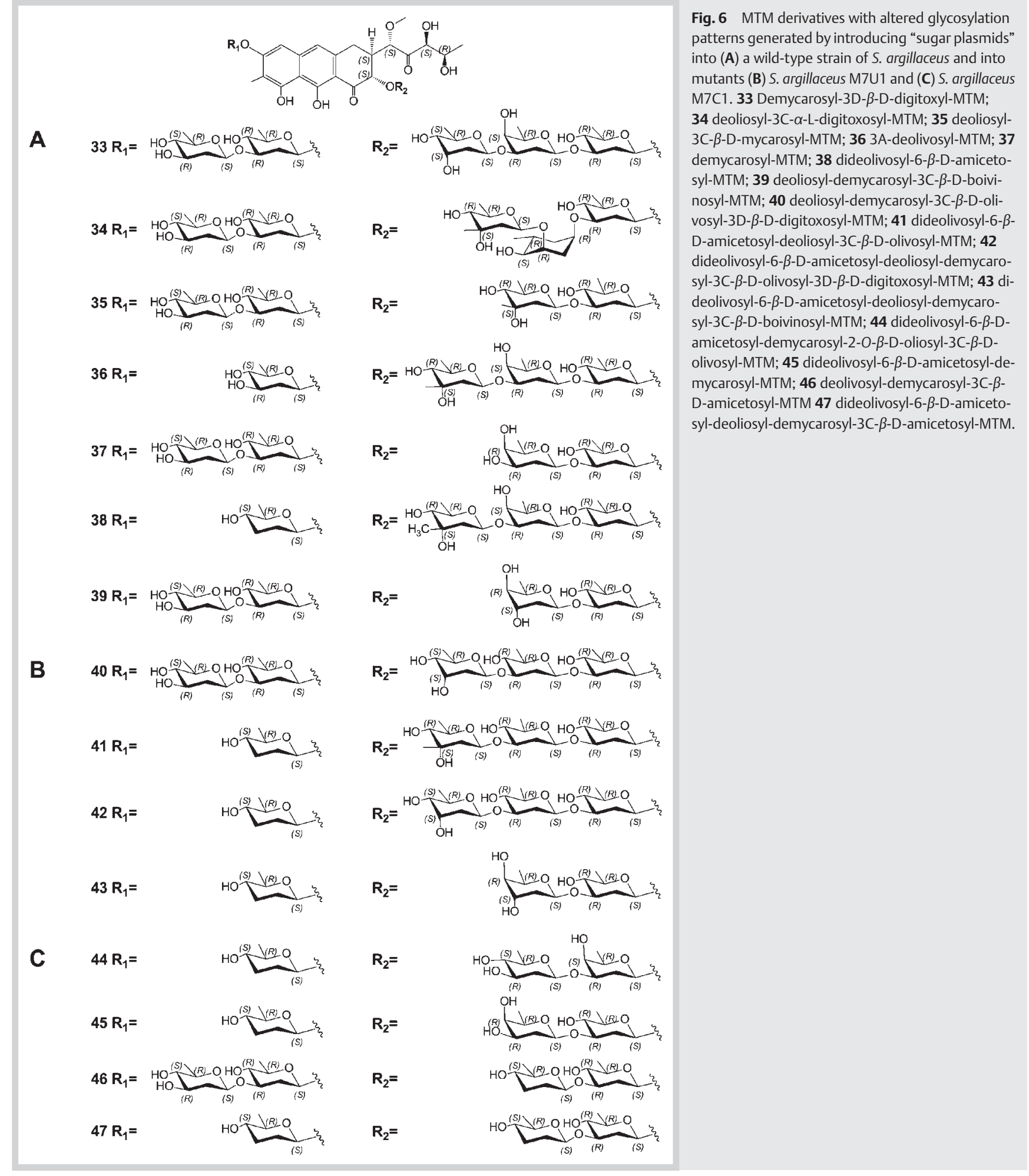

\section{Mithramycin Derivatives with Acetylated Sugars $\nabla$}

MTM is structurally related to the antitumor compound chromomycin $A_{3}$ produced by Streptomyces griseus subsp. griseus, differing in the configuration of some of the sugars and in the absence of a methyl and the presence of two acetyl groups in three chromomycin sugars. These differences impact their antitumor activity; chromomycin $\mathrm{A}_{3}$ is one order of magnitude more active than MTM [41]. The chromomycin biosynthesis gene cluster contains the acyltransferase cmmA involved in acetylating chromomycin sugars. Inactivation of this gene resulted in the production of a compound approximately 100 times less active, which highlights the importance of acetyl groups for the antitumor activity of chromomycin $A_{3}$ [42]. To produce new acetylated MTM derivatives with potentially high antitumor activity, the mutant strain S. griseus C10GIV blocked in the first glycosylation step (cmmGIV-minus mutant [43]), but expressing cmmA, was fed with MTM and different MTM derivatives. In this way, seven 
new MTM derivatives were generated that differ from MTM in the presence of one, two, or three acetyl groups attached at specific positions of different sugars of the saccharide chains as well as in the glycosylation pattern or in the structure of the aglycone



Fig. 7 Acetylated MTM derivatives generated by the bioconversion of MTMs in S. griseus C10GIV. 48 4E-O-Acetyl-MTM; 49 demycarosyl-3D- $\beta$-Ddigitoxosyl-3E-O-acetyl-MTM; 50 demycarosyl-3D- $\beta$-D-digitoxosyl-4D-Oacetyl-MTM; 51 demycarosyl-3D- $\beta$-D-digitoxosyl-4E-O-acetyl-MTM; 52 demycarosyl-3D- $\beta$-D-digitoxosyl-3E,4D-O-diacetyl-MTM; 53 demycarosyl3D- $\beta$-D-digitoxosyl-3E,4E,4D-O-triacetyl-MTM; 54 4D-O-acetyl-MTM-SK. side chain (48-54, Fig. 7) [44]. All these new mithralogs showed antitumor activity at micromolar or lower concentrations against a panel of four tumor cell lines. For example, $\mathbf{5 1}$ and $\mathbf{4 9}$ showed improved activity against glioblastoma and colon

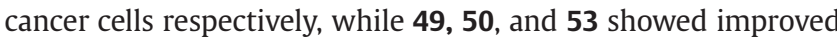
activity against pancreatic cancer tumor cells [44]. Since acetylated derivatives could be hydrolyzed in aqueous conditions compatible with biological activity, no further efforts were dedicated to this series of compounds.

\section{Mithramycin Derivatives with Modifications Both at the Aglycone Side Chain and in the Sugar Profile}

From the abovementioned novel MTM derivatives generated by combinatorial biosynthesis, both 33 ( Fig. 6) $[39,40]$ and those containing a short 3-carbon side chain, 19-22 ( $\odot$ Fig. 3), were of special interest since they showed very high antitumor activity $[23,28]$. Therefore, by providing mutant $S$. argillaceus M3W1 [23] with the capability to synthesize D-digitoxose [38], three novel derivatives were generated that differed from the parental compound in both the glycosylation pattern and the structure of the 3-carbon side chain, DIG-MTM-SK 55 and the MTM-SDK analogs 56 and 57 ( Fig. 8) [7]. All three compounds showed high antitumor activity in an NCI-60 anticancer drug screening, with $\mathrm{GI}_{50}$ values between $10 \mathrm{nM}$ and $1 \mu \mathrm{M}$ for most cell lines. DIG-MTM-SK and $\mathbf{5 7}$ showed the highest antitumor activities, being particularly active against ovarian tumor IGROVI1 and breast tumor MDA-MB-231 cell lines [7]. In a hollow fiber assay, which is an in vivo test of antiproliferative activity in multiple cancer cell lines, DIG-MTM-SK was more potent than MTM, indeed one of the most potent ever registered on the NCI records, emphasizing its potential as a broad antitumor agent. In vivo xenograft data, using colon (COLO-205) and melanoma (SK-MEL-2) models, showed efficacy, especially in melanoma, indicating the compound deserves further development. Comparison of administration schedules every other day or every three days resulted in better efficacy in the more spaced, higher dose groups, indicating DIG-MTM-SK action might depend on maximum plasma concentration rather than on plasma half-life.

\section{Generation of Mithramycin Derivatives by Biocatalysis} $\nabla$

Biocatalysis has become, in recent times, a powerful tool for optimizing complex bioactive compounds isolated from natural sources. Chemical modification of lead molecules for drug development remains challenging in structurally complex natural products, limiting the potential of organic synthesis to expand their chemical space, and is often exacerbated by the chemical fragility

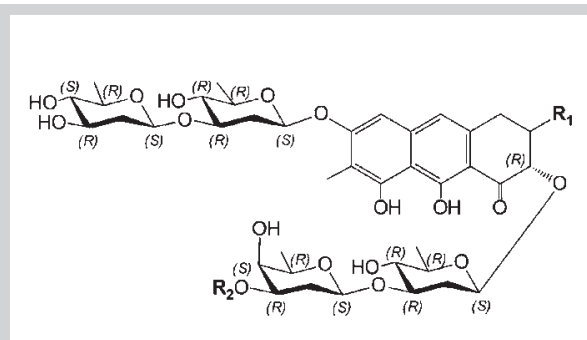

Fig. 8 MTM derivatives with both a modified 3carbon side chain and an altered glycosylation pattern, generated by introducing a plasmid for D-digitoxose into S. argillaceus M3W1. 55 Demycarosyl3D- $\beta$-D-digitoxosyl-MTM-SK; 56 demycarosylMTM-SDK; 57 demycarosyl-3D- $\beta$-D-digitoxosylMTM-SDK. 


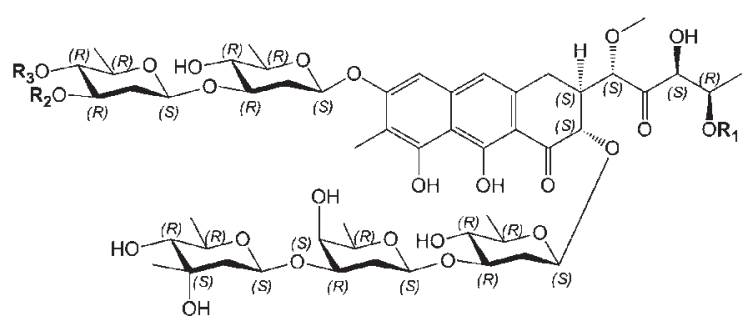

A

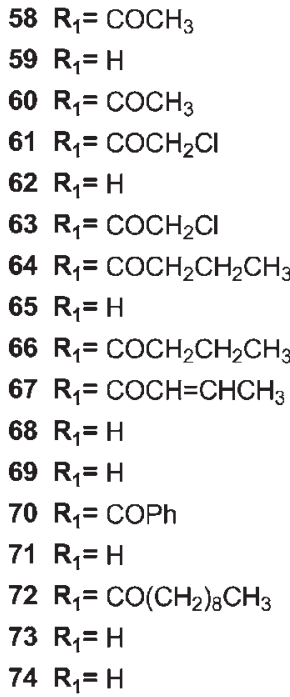

B

$$
\begin{array}{ll}
75 \mathbf{R}_{1}=\mathrm{H} \\
76 \mathbf{R}_{1}=\mathrm{COCH}_{2} \mathrm{CH}_{2} \mathrm{CO}_{2} \mathrm{H} \\
77 \mathbf{R}_{1}=\mathrm{H} \\
78 \mathbf{R}_{1}=\mathrm{H} \\
79 \mathbf{R}_{1}=\mathrm{COCH}_{2} \mathrm{CH}_{2} \mathrm{CO}_{2} \mathrm{H} \\
80 \mathbf{R}_{1}=\mathrm{COCH}_{2} \mathrm{CH}_{2} \mathrm{CO}_{2} \mathrm{H}
\end{array}
$$

$\mathbf{R}_{\mathbf{3}}=\mathrm{H}$
$\mathbf{R}_{\mathbf{3}}=\mathrm{H}$
$\mathbf{R}_{\mathbf{3}}=\mathrm{H}$
$\mathbf{R}_{\mathbf{3}}=\mathrm{H}$
$\mathbf{R}_{\mathbf{3}}=\mathrm{H}$
$\mathbf{R}_{\mathbf{3}}=\mathrm{H}$
$\mathbf{R}_{\mathbf{3}}=\mathrm{H}$
$\mathbf{R}_{\mathbf{3}}=\mathrm{H}$
$\mathbf{R}_{\mathbf{3}}=\mathrm{H}$
$\mathbf{R}_{\mathbf{3}}=\mathrm{H}$
$\mathbf{R}_{\mathbf{3}}=\mathrm{H}$
$\mathbf{R}_{\mathbf{3}}=\mathrm{H}$
$\mathbf{R}_{\mathbf{3}}=\mathrm{H}$
$\mathbf{R}_{\mathbf{3}}=\mathrm{H}$
$\mathbf{R}_{\mathbf{3}}=\mathrm{H}$
$\mathbf{R}_{\mathbf{3}}=\mathrm{H}$
$\mathbf{R}_{\mathbf{3}}=\mathrm{CO}\left(\mathrm{CH}_{2}\right)_{8} \mathrm{CH}_{3}$

$\mathbf{R}_{\mathbf{3}}=\mathrm{CO}\left(\mathrm{CH}_{2}\right)_{8} \mathrm{CH}_{3}$
Fig. 9 Acylated MTM derivatives generated by lipase catalyzed reactions employing (A) vinyl esters, (B) anhydrides and carbonates, or (C) by lipase sequential acylation. 58 4'-O-Acetyl-MTM; 59 3B-Oacetyl-MTM; 60 4',3B-O-diacetyl-MTM; 61 4'-Ochloroacetyl-MTM; 62 3B-O-chloroacetyl-MTM; 63 4',3B-O-di-chloroacetyl-MTM; 64 4'-O-butanoylMTM; 65 3B-O-butanoyl-MTM; 66 4',3B-O-dibutanoyl-MTM; 67 4'-O-crotonyl-MTM; 68 3B-O-crotonyl-MTM; 69 3B-O-cynnamoyl-MTM; 70 4'-Obenzoyl-MTM; 71 3B-O-benzoyl-MTM; 72 4'-Odecanoyl-MTM; 73 3B-O-decanoyl-MTM; 74 4B-Odecanoyl-MTM; 75 3B-O-[(allyloxy)carbonyl]-MTM; 76 4'-O-succinyl-MTM; 77 3B-O-succinyl-MTM; 78 4B-O-succinyl-MTM; 79 4',3B-O-disuccinyl-MTM; 80 4',3B-O-disuccinyl-MTM; 81 4'-O-benzoyl-3B-Oacetyl-MTM. of some of the functional groups. Biocatalysts can circumvent most of the aforementioned problems, as they exhibit high selectivity and operate under mild conditions in both aqueous and organic media. Particularly, the regioselective enzymatic acylation was one of the earliest biocatalytic transformations practiced in natural products since many of them are polyhydroxylated molecules [45]. Accordingly, MTM, which bears 9 hydroxyl groups in both the oligosaccharide and aglycone domains, was selectively acylated by lipases A and B from Candida antarctica (CAL-A and CAL-B) to provide 22 new mithralogs, 58-80 (- Fig. 9A, B) [46]. Specifically, CAL-B was highly regioselective towards the 4'-hydroxyl group of the aglycone, and sterically hindered or poorly reactive esters provided the corresponding 4'-monoacyl derivatives in excellent yields. On the other hand, the use of more reactive acyl donors led to mixtures of mono- and diacylated derivatives in the 4' and 3B-hydroxyl groups. CAL-A, meanwhile, showed regioselectivity towards the dissacharide domain, acylating the 3B- or 4B-hydroxyl groups exclusively. As a result, and just by changing the acylating agent, a plethora of mono- and diacylated mithralogs were obtained ( 0 Fig. 9 ). Furthermore, the different regioselectivity of the lipases allowed their use in a se- quential mode to produce mixed diacylated products, such as $\mathbf{8 1}$ ( Fig. 9C). Consequently, the structure of MTM can be tuned by a rational design of the acylation sequence, multiplying the number of possible derivatives and expanding the molecular diversity of this aureolic acid scaffold.

Similarly, MTM-SK and MTM-SDK ( Fig. 3) were also submitted to enzymatic acylation leading to novel mithralogs by combining genetic engineering and biocatalysis. These compounds were acylated by CAL-B and CAL-A in the hydroxyl groups of the 3B and $4 \mathrm{~B}$ positions of the disaccharide, with the aglycone remaining unaltered, providing several acylated MTM derivatives, such as 82-90 ( $\odot$ Fig. 10). It is worth highlighting that the biocatalytic acylation is complementary to the genetic engineering approach described above for the generation of MTM derivatives with acetylated sugars ( Fig. 7). In that case, by expressing the acyltransferase $c m m A$, it was possible to acylate hydroxyl groups of sugars $\mathrm{D}$ and $\mathrm{E}$ only ( Fig. 7), while lipases can act over both aglycone and sugar B ( Figs. 9 and 10).

Along these libraries of acyl derivatives ( Figs. 9 and 10), some exhibited potency comparable to, or slightly greater than, the parent drugs. For example, 59 ( Fig. 9) was better than MTM 

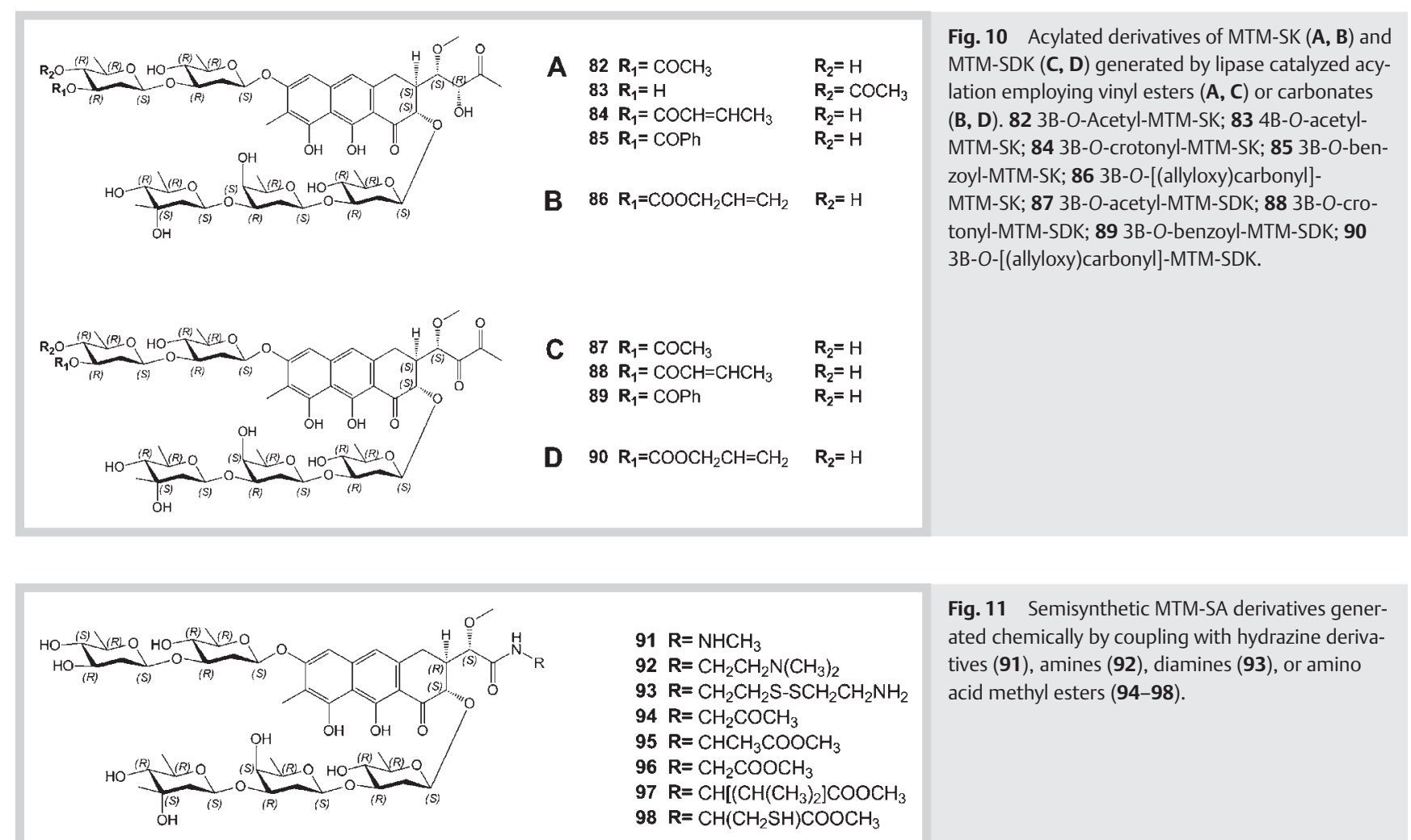

Fig. 11 Semisynthetic MTM-SA derivatives generated chemically by coupling with hydrazine derivatives (91), amines (92), diamines (93), or amino acid methyl esters (94-98). against lung (A549), colon (CoLo 205), and breast (MCF7) tumor cells, and 72 ( Fig. 9) was the most effective against A498 renal tumor cells. Also, 87 ( $\odot$ Fig. 10) showed notably higher activity than the parental MTM-SDK, as judged by GI $_{50}$ values 2 to 4 times lower in colon (CoLo 205), ovary (OVCAR-3), lung (A549), and renal (A498) cancer cell lines [46]. On the other hand, acetylated compounds in the sugar domain are prone to hydrolysis in aqueous conditions, which limits their use in vivo due to instability reasons [46].

\section{Semisynthetic Approaches \\ $\nabla$}

Due to the high level of functionalization of aureolic acids, it has been difficult to modify their structure by semisynthesis. Thus, most of the chemically modified aureolic acid derivatives have been reported for olivomycin A, with the changes focusing only on the side chain of the aglycone moiety [47-49]. Regarding MTM, the only reported example is the modification of $\mathbf{2 1}$ (MTM-SA), which bears a short 3-carbon side chain with a carboxylic acid, a negative charge that causes repulsion with the DNA phosphate backbone, which is presumably the reason for the poor activity of MTM-SA. The acid function reacted with several primary amines to provide amide analogs 91-98 (๑ Fig. 11), and their activity was measured in A549 lung tumor cells. Some derivatives showed a notably improved activity with respect to MTM-SA, particularly, the derivative coupled with methyl glycine 95 showed comparable activity to that of MTM-SK [50].

\section{Bioactivity of New Mithramycin Derivatives $\nabla$}

Further studies regarding the mechanism of action or in vivo activity were carried out on selected mithralogs, mainly MTM-SK, MTM-SDK, and DIG-MTM-SK. The initial driver to focus on these three compounds was the differential properties with respect to other analogs. In the case of MTM-SDK, it was because of its increased antitumor activity, and in the case of MTM-SK and DIG-MTM-SK, it was because of the much lower toxicity in vivo [7]. OTable 1 summarizes the results of the studies carried out on these mithralogs.

Early studies showed that changes in the aglycone caused MTM analogs to lose their ability to bind DNA, except the analog modified in the side chain, MTM-SK, that showed the same DNA binding specificity but with lower binding affinity than MTM [51]. Its weaker interaction with DNA hinted at the possibility of being much less toxic than MTM. This fact was supported by comparing the cytotoxicity of MTM and MTM-SK using 3T3 mouse fibroblasts, resulting in MTM-SK being 1500-fold less toxic than MTM [23]. In vitro studies of MTM-SK in colon cancer cell lines, both wild type or with inactivation of p53 and p21, contribute to understanding the mechanism of action of the drug, especially regarding cell cycle and cell death. Treatment of wild-type HCT$116\left(\mathrm{p} 53^{+/+}\right)$colon carcinoma cells with MTM-SK results in polyploidization and mitotic catastrophe, which occurs after a transient halt in the $\mathrm{G} 1$ phase followed by the overtaking of the G2-M checkpoint upon a washout period. Cells died mainly by necrosis, involving caspase-3. However, $\mathrm{p} 53^{-/-}$cells died mainly following G2-M arrest by p53-independent apoptosis, which appeared to be mediated by caspase-2 [52]. In a follow-up study, treatment of HCT-116 p21( $\left(^{-I^{-}}\right)$, a p21 deficient human colon carcinoma cell line, caused transient arrest in G2-M, with some cells entering a faulty mitotic cycle without cytokinesis that resulted 
Table 1 Studies on the biological effects and mechanism of action of selected mithralogs.

\begin{tabular}{|c|c|}
\hline Mithralog [reference] & Major results \\
\hline MTM-SK [51] & $\begin{array}{l}\text { - MTM-SK is comparable to MTM in promoter reporter, gene expression, and DNA binding specificity } \\
\text { - MTM-SK shows lower DNA binding affinity than MTM, which might hint at a lower toxicity than MTM }\end{array}$ \\
\hline MTM-SK [23] & $\begin{array}{l}\text { MTM-SK is up to 9× more active than MTM in some cell lines, MTM-SK is 1500× less toxic than MTM in } 3 \text { T3 mouse fibroblasts; im- } \\
\text { proved in vitro therapeutic index }\end{array}$ \\
\hline MTM-SDK, MTM-SK [28] & $\begin{array}{l}\text { Antiproliferative activity on seven ovarian cancer cell lines; MTM-SDK twice as active as MTM-SK or MTM } \\
\text { - MTM-SDK is a potent inducer of apoptosis and it has minimal effects on normal cells } \\
\text { - MTM-SDK is a potent inhibitor of Sp1 reporter activity and interferes minimally with other transcription factors } \\
\text { - MTM-SDK gene expression microarray (A2780 cell line) shows repressed transcription of genes implicated in cell cycle, apoptosis, } \\
\text { migration, invasion, and angiogenesis }\end{array}$ \\
\hline MTM-SK [52] & $\begin{array}{l}\text { MTM-SK treatment causes mitotic catastrophe and polyploidy in HCT-116 }\left(\mathrm{p} 53^{+++}\right) \text {cells } \\
\text { HCT-116 }\left(\mathrm{p} 53^{+/+}\right) \text {colon carcinoma cells are committed to die by necrosis rather than apoptosis even in presence of active caspase- } 3 \text {, } \\
\text { but p } 53^{-1} \text { cells die by apoptosis mediated by caspase- } 2\end{array}$ \\
\hline MTM-SK [53] & $\begin{array}{l}\text { Apoptosis in MTM-SK-treated HCT- } 116 \text { p } 21 \text { - colon cancer cells involves caspase- } 2 \text { rather than caspase-3 } \\
\text { - The absence of } 211^{\text {WAF1 }} \text { makes HCT116 cells more sensitive to MTM-SK than to MTM } \\
\text { - MTM-SK treatment activates caspase- } 3 \text { in wild-type HCT116 } \\
\text { - MTM-SK is more active than MTM on HCT116 cells lacking the p } 53 \text { gene }\end{array}$ \\
\hline MTM, MTM-SK & $\begin{array}{l}\text { DNA binding of MTM (UV melting and competition dialysis) is tighter than that of MTM-SK at } 25^{\circ} \mathrm{C} \\
\text { DNA binding of MTM and MTM-SK is entropically driven; hydrophobic transfer from solution to binding site }\end{array}$ \\
\hline $\begin{array}{l}\text { MTM, MTM-SK } \\
\text { MTM-SDK, MTM-SA [55] }\end{array}$ & $\begin{array}{l}\text { DNA binding shows differences depending on the alkyl chains linked to } \mathrm{C}-3 \text { in the mithramycin analogs } \\
\text { - MTM-SDK has the highest binding affinity to DNA }\end{array}$ \\
\hline $\begin{array}{l}\text { MTM, MTM-SK, } \\
\text { MTM-SDK, MTM-SA [56] }\end{array}$ & $\begin{array}{l}\text { - Analogs differentially inhibit the rate of cleavage by restriction enzymes that recognize C/G-rich tracts } \\
\text { - Correlation between the strength of binding to DNA and antiproliferative activity } \\
\text { - Differences in the uptake and retention correlate to improved antiproliferative activities }\end{array}$ \\
\hline MTM-SDK, MTM-SK [57] & $\begin{array}{l}\text { Expression of Sp1 and VEGF are frequently increased in human epithelial ovarian cancers } \\
\text { - MTM-SDK and MTM-SK act as potent inhibitors of Sp1-dependent transcription both in vitro and in vivo } \\
\text { - Both are well tolerated in mice and delay growth of subcutaneous ovarian tumor xenografts } \\
\text { - MTM-SDK is effective in orthotopic tumors; significant delay of tumor progression }\end{array}$ \\
\hline MTM-SDK, MTM-SK [58] & $\begin{array}{l}\text { Both are highly effective in vitro in inhibiting proliferation of prostate cancer cells and transcription of Sp-regulated genes } \\
\text { - Both are well tolerated with maximum tolerated doses } 4 \times \text { (MTM-SDK) and } 32 \times \text { (MTM-SK) higher than MTM } \\
\text { - Both compounds are cleared rapidly from the bloodstream in mice, but maintain plasma levels well above the concentrations } \\
\text { required in vitro for inhibition of Sp activity and cell proliferation } \\
\text { - MTM-SDK and MTM-SK inhibit transcription of Sp-regulated genes in prostate tumor xenografts } \\
\text { - MTM-SDK and MTM-SK exhibit potent antitumor activity in a prostate tumor model } \\
\text { - MTM-SDK and MTM-SK inhibit metastasis to the lung in a metastatic prostate tumor model }\end{array}$ \\
\hline DIG-MTM [40] & $\begin{array}{l}\text { - Antiproliferative assays: } I C_{50} \text { for DIG-MTM is low double-digit nanomolar, similar to MTM } \\
\text { - Compounds lacking a trisaccharide unit are } 5 \text { - to } 100 \text {-fold less active }\end{array}$ \\
\hline DIG-MTM [39] & $\begin{array}{l}\text { DIG-MTM induces higher apoptosis than MTM in ER-human breast cancer cell lines } \\
\text { DIG-MTM, but not MTM, induces apoptosis in ER+ human breast cancer cell lines }\end{array}$ \\
\hline $\begin{array}{l}\text { Biocatalysis mithralogs } \\
{[44,46]}\end{array}$ & $\begin{array}{l}\text { - Antiproliferative assays; data similar to MTM } \\
\text { - Stability in physiological saline at } 37^{\circ} \mathrm{C} \text {; acetylated compounds hydrolyze significantly }\end{array}$ \\
\hline DIG-MTM-SK [7] & $\begin{array}{l}\text { Antiproliferative activity by NCl-60 panel comparison shows 2-7× improvement of DIG-MTM-SK over DIG-MTM } \\
\text { DIG-MTM-SK maximum intravenous tolerated dose (MTD) in mice is } 64 \mathrm{mg} / \mathrm{Kg} \text {. For repeated doses (up to } 8 \text { times) every other day, } \\
\text { MTD is } 12 \mathrm{mg} / \mathrm{Kg} \text {, and every } 3 \text { days MTD is } 24 \mathrm{mg} / \mathrm{Kg} \\
\text { - Similar PK profile to MTM and MTM-SK in mice after intravenous administration, but maximum concentration achieved is } 10 \times \text { higher } \\
\text { than in MTM } \\
\text { - Significant growth inhibition in subcutaneous xenografts of colon and melanoma cell lines, better response with a high, more spaced } \\
\text { dose }\end{array}$ \\
\hline $\begin{array}{l}\text { MTM-SK, DIG-MTM-SK } \\
{[60]}\end{array}$ & $\begin{array}{l}\text { DIG-MTM-SK has a higher effect than MTM-SK on gene transcription of } 89 \text { cell cycle genes in colon cancer cells; only } 5 \text { genes down- } \\
\text { regulated by both drugs } \\
\text { p21 }\end{array}$ \\
\hline DIG-MTM-SK [61] & DIG-MTM-SK is being explored in the treatment of Ewing sarcoma tumor cells \\
\hline $\begin{array}{l}\text { MTM-SK, DIG-MTM-SK } \\
\text { [62] }\end{array}$ & $\begin{array}{l}\text { DIG-MTM-SK is a potent inhibitor of both basal and induced expression of Sp1 } \\
\text { DIG-MTM-SK is stronger than MTM as an inhibitor of Sp3-driven transcription and endogenous Sp3 gene expression } \\
\text { - MTM, MTM-SK, and DIG-MTM-SK accumulate rapidly in ovarian cancer cell lines }\end{array}$ \\
\hline DIG-MTM-SK [63] & $\begin{array}{l}\text { Gene expression array; nanomolar levels of DIG-MTM-SK abrogate expression of genes involved in transcription regulation and tumor } \\
\text { development in A2780 ovarian cancer cells } \\
\text { - Other non-Sp binding sites identified: CREB, E2F, and EGR1 }\end{array}$ \\
\hline
\end{tabular}

in G1-like cell arrest, which consisted of post-mitotic aneuploid G1 cells. Apoptosis in p21(-/-) cells involved caspase 2 rather than caspase 3, as in the wild-type cells [53].

Another mithralog that deserved early attention was MTM-SDK, since it was more potent than MTM and MTM-SK according to antiproliferative assays, including the NCI-60 panel. In ovarian cancer cell lines, the mechanism of action was consistent with the repression of transcription of multiple genes implicated in critical aspects of cancer development and progression, including cell cycle, apoptosis, migration, invasion, and angiogenesis, which is in agreement with the pleiotropic role of Sp1 family transcription factors [28]. MTM-SDK inhibited proliferation and was a po- 
tent inducer of apoptosis in ovarian cancer cells, while it had minimal effects on the viability of normal cells.

Both MTM-SK and MTM-SDK have been the subject of several comparative studies. The thermodynamic profile of MTM binding to DNA was compared to that of MTM-SK, showing that the binding to DNA is entropically driven and dominated by the hydrophobic transfer of the antibiotics from the solution to the DNA binding site [54]. In a follow-up study, comparing the binding of MTM-SK, MTM-SDK, and MTM-SA, including a molecular modeling analysis of the impact of the side chain on binding, it was found that MTM-SDK has the highest binding affinity [55]. Differential cleavage at three restriction enzyme sites was used to determine the specific binding to DNA of MTM and shorter side chain analogs. Together with changes in the DNA melting temperature and cellular uptake, these experimental approaches provided mutually consistent evidence of a correlation between the strength of binding to DNA and the antiproliferative activity of the chromophore-modified molecules. Interestingly, the authors reported a link between antiproliferative activity and intracellular accumulation (measured in HCT-116 and PC3 cell lines), since the most bioactive compounds are also the ones accumulated and retained over $72 \mathrm{~h}$ periods [56].

In addition, MTM-SDK and MTM-SK acted as potent inhibitors of Sp1-dependent transcription both in vitro and in tumor xenografts. Both compounds were well tolerated even after prolonged administration and delayed growth of ovarian tumor xenografts. MTM-SDK was particularly effective against orthotopic tumors, leading to a significant increase of survival and delay of tumor progression [57]. Regarding prostate cancer, MTM-SDK and MTM-SK were highly effective in vitro in inhibiting the proliferation of prostate cancer cells and transcription of Sp-regulated genes by blocking the binding of Sp proteins to the gene promoters. When administered to mice, both compounds were well tolerated and were cleared rapidly from the bloodstream, but they maintained plasma levels well above the active concentrations required in vitro for the inhibition of Sp activity and cell proliferation. Consistently, MTM-SDK and MTM-SK inhibited the transcription of Sp-regulated genes in prostate tumor xenografts and exhibited potent antitumor activity in both subcutaneous as well as metastatic tumor xenograft models with no or minimal toxicity [58]. The pharmacokinetic profile is similar to MTM and other mithralogs in terms of half-life, however, the maximum plasma concentration is much higher, one order of magnitude higher than MTM. This is very important, since in humans, the reported maximum plasma concentration for MTM is $<20 \mathrm{nM}$, insufficient to achieve therapeutic action, according to the $\mathrm{IC}_{50}$ for most cancer cell lines [59].

DIG-MTM-SK is the most promising mithralog since it has the highest in vivo maximum tolerated dose in mice, and thus the lowest toxicity among all mithralogs tested [7]. Since the in vitro and in vivo activity on cell lines or xenotransplants was similar or better than MTM, DIG-MTM-SK represents a real opportunity to increase the therapeutic window of MTM-based drugs.

The influence of DIG-MTM-SK and MTM-SK on the transcription of 89 genes mainly involved in cell cycle control in human HCT116 colon carcinoma cells by qRT-PCR was analyzed. Each compound downregulated a different set of genes. Indeed, only five genes were downregulated by both compounds. Other genes were significantly upregulated, among them p21 WAF1/CDKN1 A, which is involved in halting cells at the G1 and G2-M checkpoints. It is of note that just the minor structural change from DIG-MTM-SK to MTM-SK produces such a clear dissimilarity in their "anti-transcriptional" activity. DIG-MTM-SK seems to be a superior molecule, since abrogation of a larger number of genes was observed (meaning there is a disruption of more interactions between transcription factors and their consensus binding sites in a tumor cell). Also, DIG-MTM-SK seems to have a stronger effect in terms of the upregulation of genes responsive to cell damage [60].

The activity of DIG-MTM-SK is related to its binding to DNA, cellular accumulation, and inhibition of Sp1-driven gene transcription, as shown in ovarian cancer cell lines in vitro. The binding of DIG-MTM-SK to DNA shares the general features of other mithralogs, such as the preference for $\mathrm{C} / \mathrm{G}$-rich tracts, but there are some differences in the strength of binding and the DNA sequence preferentially recognized by DIG-MTM-SK. Similar to MTM, both MTM-SK and DIG-MTM-SK accumulated rapidly in A2780, IGROV1, and OVCAR3 human ovarian cancer cell lines. Also, DIG-MTM-SK was a potent inhibitor of both basal and induced expression of an Sp1-driven luciferase vector. Furthermore, DIG-MTM-SK was stronger than MTM as an inhibitor of Sp3-driven transcription and endogenous Sp3 gene expression [62].

Using a genome-wide approach, gene expression in A2780 human ovarian carcinoma cells treated with DIG-MTM-SK was studied. Nanomolar concentrations of DIG-MTM-SK abrogated the expression of the genes involved in a variety of cell processes, including transcription regulation and tumor development. Some of those genes have been associated with cell proliferation and poor prognosis in ovarian cancer. Sp1 regulated most of the genes that were downregulated by the drug. The effect of DIG-MTM-SK in the control of gene expression by other transcription factors was also explored. Some of them, such as CREB, E2F, and EGR1, also recognize C/G-rich regions in gene promoters, which encompass potential DIG-MTM-SK binding sites [63].

DIG-MTM-SK, among other mithralogs, is being evaluated to identify a candidate for Ewing sarcoma, a particularly deadly form of cancer [61]. MTM was identified as a candidate out of 50000 molecules at the $\mathrm{NCI}$ and is being tested in phase I clinical trials [2].

\section{Conclusion and Future Directions} $\nabla$

The growing body of literature on MTM and its main target Sp1 transcription factor is mostly related to novel mechanisms of action relevant to several diseases, mainly cancer. This fact, together with the recent launch of MTM clinical trials in certain tumors for the first time in decades, has fueled a renewed interest in this promising natural product scaffold.

In the quest for novel mithralogs, the most successful criteria to date has been to identify analogs that allow higher tolerated doses to circumvent the main problem reported in MTM development history, toxicity. Since these analogs are also selected based in their in vitro and in vivo activity, they might have a chance of expanding the therapeutic window of MTM. Moreover, such higher tolerated doses are also linked to better plasma levels in animals, which could potentially circumvent the recently identified problem in MTM of low circulating levels in humans (reflecting the same situation in animals).

Another area of future research is to identify molecular characteristics that would render certain cancer cells more sensitive to the mithralogs. Typically, these would be overexpressed genes or protein targets, and the advances in proteomics and genomics 
will help to unravel the pleiotropic mechanism of action of these kinds of drugs. It is of note that complex natural products, like mithralogs, are designed by nature to interact with membranes through transporters, so a future direction is the study of the differential accumulation in cancer cells, which, if found relevant, is likely to be mediated by active rather than passive transport.

The main priority in the development of mithralogs is to verify the promising toxicity and PK data in humans. For this purpose, an FHI trial will be designed to identify doses, schedules, and plasma levels in order to optimize human doses with the potential of being pharmacologically active in patients.

\section{Acknowledgements}

$\nabla$

This work was supported by grants from the Spanish Ministry of Economy and Competitiveness to C.M. (BIO2005-04115, PET2005-0401 and BIO2011-25398) and J.A. S (BIO-0771), and from Red del cancer (FISS-06-RD06/0020/0026) and Principado de Asturias (PR-01-GE-16) to J.A.S.

\section{Conflict of Interest}

\section{$\nabla$}

F.M. and J.G.S. are employees of EntreChem S.L., and C.M., F.M., and J.A.S. hold shares of EntreChem S. L.

\section{References}

1 González-Sabín J, Morís F. Exploring novel opportunities for aureolic acids as anticancer drugs. Biochem \& Pharmacol 2013; 2: e140

2 Grohar PJ, Woldemichael GM, Griffin LB, Mendoza A, Chen QR, Yeung C, Currier DG, Davis S, Khanna C, Khan J, McMahon JB, Helman LJ. Identification of an inhibitor of the EWS-FLI1 oncogenic transcription factor by high-throughput screening. J Natl Cancer Inst 2011; 103: 962-978

3 Zhang M, Mathur A, Zhang Y, Xi S, Atay S, Hong JA, Datrice N, Upham T, Kemp CD, Ripley RT, Wiegand G, Avital I, Fetsch P, Mani H, Zlott D, Robey R, Bates SE, Li X, Rao M, Schrump DS. Mithramycin represses basal and cigarette smoke-induced expression of ABCG2 and inhibits stem cell signaling in lung and esophageal cancer cells. Cancer Res 2012; 72: 4178-4192

4 Boichuk S, Lee DJ, Mehalek KR, Makielski KR, Wozniak A, Seneviratne DS, Korzeniewski N, Cuevas R, Parry JA, Brown MF, Zewe J, Taguchi T, Kuan SF, Schöffski P, Debiec-Rychter M, Duensing A. Unbiased compound screening identifies unexpected drug sensitivities and novel treatment options for gastrointestinal stromal tumors. Cancer Res 2014; 74: 1200-1213

5 Vanner RJ, Remke M, Gallo M, Selvadurai HJ, Coutinho F, Lee L, Kushida M, Head R, Morrissy S, Zhu X, Aviv T, Voisin V, Clarke ID, Li Y, Mungall AJ, Moore RA, Ma Y, Jones SJ, Marra MA, Malkin D, Northcott PA, Kool M, Pfister SM, Bader G, Hochedlinger K, Korshunov A, Taylor MD, Dirks PB. Quiescent sox2(+) cells drive hierarchical growth and relapse in sonic hedgehog subgroup medulloblastoma. Cancer Cell 2014; 26: 33-47

6 Smolewski P. Terameprocol, a novel site-specific transcription inhibitor with anticancer activity. IDrugs 2008; 11: 204-214

7 Núñez LE, Nybo SE, Gonzalez-Sabin J, Pérez M, Menéndez N, Braña AF, He $M$, Morís F, Salas JA, Rohr J, Méndez C. A novel mithramycin analogue with high antitumor activity and less toxicity generated by combinatorial biosynthesis. J Med Chem 2012; 55: 5813-5825

8 Lombó F, Menéndez N, Salas JA, Méndez C. The aureolic acid family of antitumor compounds: structure, mode of action, biosynthesis and novel derivatives. Appl Microbiol Biotechnol 2006; 73: 1-14

9 Lombó F, Braña AF, Méndez C, Salas JA. The mithramycin gene cluster of Streptomyces argillaceus contains a positive regulatory gene and two repeated DNA sequences that are located at both ends of the cluster. J Bacteriol 1999; 181: 642-647

10 Blanco G, Fu H, Méndez C, Khosla C, Salas JA. Deciphering the biosynthetic origin of the aglycone of the aureolic acid group of anti-tumor agents. Chem Biol 1996; 3: 193-196
11 Lombó F, Blanco G, Fernández E, Méndez C, Salas JA. Characterization of Streptomyces argillaceus genes encoding a polyketide synthase involved in the biosynthesis of the antitumor mithramycin. Gene 1996; 172: 87-91

12 Prado L, Lombó F, Braña AF, Méndez C, Rohr J, Salas JA. Analysis of two chromosomal regions adjacent to a type II polyketide synthase involved in the biosynthesis of the antitumor polyketide mithramycin in Streptomyces argillaceus. Mol Gen Genet 1999; 261: 216-225

13 Abdelfattah MS, Rohr J. Premithramycinone G, an early shunt product of the mithramycin biosynthetic pathway accumulated upon inactivation of oxygenase MtmOII. Angew Chem Int Ed Engl 2006; 45: 5685-5689

14 Lozano MJ, Remsing LL, Quirós LM, Braña AF, Fernández E, Sánchez C, Méndez C, Rohr J, Salas JA. Characterisation of two polyketide methyltransferases involved in the biosynthesis of the antitumor drug mithramycin by Streptomyces argillaceus. J Biol Chem 2000; 275: 3065-3074

15 Blanco G, Fernández E, Fernández MJ, Braña AF, Weißbach U, Künzel E, Rohr J, Méndez C, Salas JA. Characterization of two glycosyltransferases involved in early glycosylation steps during biosynthesis of the antitumor polyketide mithramycin by Streptomyces argillaceus. Mol Gen Genet 2000; 262: 991-1000

16 Wang G, Pahari P, Kharel MK, Chen J, Zhu H, Van Lanen SG, Rohr J. Cooperation of two bifunctional enzymes in the biosynthesis and attachment of deoxysugars of the antitumor antibiotic mithramycin. Angew Chem Int Ed Engl 2012; 51: 10638-10642

17 Rodríguez D, Quirós LM, Salas JA. MtmMII-mediated C-methylation during biosynthesis of the antitumor drug mithramycin is essential for biological activity and DNA-drug interaction. J Biol Chem 2004; 279: 8149-8158

18 Fernández E, Weibbach U, Sánchez Reillo C, Braña AF, Méndez C, Rohr J, Salas JA. Identification of two genes from Streptomyces argillaceus encoding two glycosyltransferases involved in the transfer of a disaccharide during the biosynthesis of the antitumor drug mithramycin. J Bacteriol 1998; 180: 4929-4937

19 Nur-e-Alam M, Méndez C, Salas JA, Rohr J. Elucidation of the glycosylation sequence of mithramycin biosynthesis: isolation of 3 A-deolivosylpremithramycin B and its conversion to premithramycin B by glycosyltransferase MtmGII. Chembiochem 2005; 6: 632-636

20 Prado L, Fernández E, Weisbach U, Blanco G, Quirós LM, Braña AF, Mén$\operatorname{dez}$ C, Rohr J, Salas JA. Oxidative cleavage of premithramycin B is one of the last steps in the biosynthesis of the antitumor drug mithramycin. Chem Biol 1999; 6: 19-30

21 Rodríguez D, Quirós LM, Braña AF, Salas JA. Purification and characterization of a monooxygenase involved in the biosynthetic pathway of the antitumor drug mithramycin. J Bacteriol 2003; 185: 3962-3965

22 Gibson M, Nur-e-alam M, Lipata F, Oliveira MA, Rohr J. Characterization of kinetics and products of the Baeyer-Villiger oxygenase MtmOIV, the key enzyme of the biosynthetic pathway toward the natural product anticancer drug mithramycin from Streptomyces argillaceus. J Am Chem Soc 2005; 127: 17594-17595

23 Remsing LL, González AM, Nur-e-Alam M, Fernández-Lozano MJ, Braña AF, Rix U, Oliveira MA, Méndez C, Salas JA, RohrJ. Mithramycin SK, a novel antitumor drug with improved therapeutic index, mithramycin SA, and demycarosyl-mithramycin SK: three new products generated in the mithramycin producer Streptomyces argillaceus through combinatorial biosynthesis. J Am Chem Soc 2003; 125: 5745-5753

24 Fernández E, Lombó F, Méndez C, Salas JA. An ABC transporter is essential for resistance to the antitumor agent mithramycin in the producer Streptomyces argillaceus. Mol Gen Genet 1996; 251: 692-698

25 Salas JA, Méndez C. Genetic manipulation of antitumor-agents biosynthesis: a potential method for developing novel drugs. Trends Biotechnol 1998; 16: 475-482

26 González A, Lombó F, Fernández Lozano MJ, Prado L, Braña AF, Rohr J, Méndez C, Salas JA. The mtmCUV genes of the antitumor mithramycin gene cluster are involved in the biosynthesis of the sugar moieties. Mol Gen Genet 2001; 264: 827-835

27 Remsing LL, García-Bernardo J, González A, Künzel E, Rix U, Braña AF, Bearden DW, Méndez C, Salas JA, Rohr J. Ketopremithramycins and ketomithramycins, four new aureolic acid-type compounds obtained upon inactivation of two genes involved in the biosynthesis of the deoxysugar moieties of the antitumor drug mithramycin by Streptomyces argillaceus, reveal novel insights into post-PKS tailoring steps of the mithramycin biosynthetic pathway. J Am Chem Soc 2002; 124: 1606-1614

28 Albertini V, Jain A, Vignati S, Napoli S, Rinaldi A, Kwee I, Nur-e-Alam M, Bergant J, Bertoni F, Carbone GM, Rohr J, Catapano CV. Novel GC-rich DNA-binding compound produced by a genetically engineered mutant 
of the mithramycin producer Streptomyces argillaceus exhibits improved transcriptional repressor activity: implications for cancer therapy. Nucleic Acids Res 2006; 34: 1721-1734

29 Kunnari T, Klika KD, Blanco G, Méndez C, Mantsala P, Hakala J, Sillanpaa $R$, Tahtinen P, Salas JA, Ylihonko K. Hybrid compounds generated by the introduction of a nogalamycin-producing plasmid into Streptomyces argillaceus. J Chem Soc Perkin Trans I 2002; 1818-1825

30 Lombó F, Künzel E, Prado L, Braña AF, Bindseil KU, Frevert J, Bearden D, Méndez C, Salas JA, Rohr J. The novel hybrid antitumor compound premithramycinone $\mathrm{H}$ provides indirect evidence for a tricyclic intermediate of the biosynthesis of the aureolic acid antibiotic mithramycin. Angew Chem Int Ed Engl 2000; 112: 808-811

31 Wang G, Kharel MK, Pahari P, Rohr J. Investigating mithramycin deoxysugar biosynthesis: enzymatic total synthesis of TDP-D-olivose. Chembiochem 2011; 12: 2568-2571

32 Künzel E, Faust B, Oelkers C, Weissbach U, Bearden DW, Weitnauer G, Westrich L, Bechthold A, Rohr J. Inactivation of the urdGT2 gene, which encodes a glycosyltransferase responsible for the C-glycosyltransfer of activated D-olivose, leads to formation of the novel urdamycins I, J, and K. J Am Chem Soc 1999; 121: 11058-11062

33 Trefzer A, Blanco G, Remsing L, Künzel E, Rix U, Lipata F, Braña AF, Méndez C, Rohr J, Bechthold A, Salas JA. Rationally designed glycosylated premithramycins: hybrid aromatic polyketides using genes from three different biosynthetic pathways. J Am Chem Soc 2002; 124: 6056-6062

34 Trefzer A, Fischer C, Stockert S, Westrich L, Künzel E, Girreser U, Rohr J, Bechthold A. Elucidation of the function of two glycosyltransferase genes (lanGT1 and lanGT4) involved in landomycin biosynthesis and generation of new oligosaccharide antibiotics. Chem Biol 2001; 8: $1239-1252$

35 Rodríguez L, Aguirrezabalaga I, Allende N, Braña AF, Méndez C, Salas JA. Engineering deoxysugar biosynthetic pathways from antibiotic-producing microorganisms: a tool to produce novel glycosylated bioactive compounds. Chem Biol 2002; 9: 721-729

36 Lombó F, Gibson M, Greenwell L, Braña AF, Rohr J, Salas JA, Méndez C. Engineering biosynthetic pathway for deoxysugars: branched-chain sugar pathways and novel derivatives from the antitumor tetracenomycin. Chem Biol 2004; 11: 1709-1718

37 Pérez M, Lombó F, Zhu L, Gibson M, Braña AF, Rohr J, Salas JA, Méndez C. Combining sugar biosynthesis gene cassettes to generate two glycosylated antitumor tetracenomycins. Chem Commun (Camb) 2005; 12: 1604-1606

38 Pérez M, Lombó F, Baig I, Braña AF, Rohr J, Salas JA, Méndez C. Combining sugar biosynthesis genes for the generation of L- and D-amicetose and formation of two novel antitumor tetracenomycins. Appl Environ Microbiol 2006; 72: 6644-6652

39 Baig I, Perez M, Braña AF, Gomathinayagam R, Damodaran C, Salas JA, Méndez C, RohrJ. Mithramycin analogs generated by combinatorial biosynthesis show improved bioactivity. J Nat Prod 2008; 71: 199-207

40 Pérez M, Baig I, Braña AF, Salas JA, Rohr J, Méndez C. Generation of new derivatives of the antitumor antibiotic mithramycin by altering the glycosylation pattern through combinatorial biosynthesis. Chembiochem 2008; 9: 2295-2304

41 Menéndez N, Mohammad N, Braña AF, Rohr J, Salas JA, Méndez C. Biosynthesis of the antitumor chromomycin $\mathrm{A}_{3}$ in Streptomyces griseus: analysis of the gene cluster and rational design of novel chromomycin analogues. Chem Biol 2004; 11: 21-32

42 Menéndez N, Nur-e-Alam M, Braña AF, Rohr J, Salas JA, Méndez C. Tailoring modification of deoxysugars during biosynthesis of the antitumor drug chromomycin $\mathrm{A}_{3}$ by Streptomyces griseus subsp. griseus. Mol Microbiol 2004; 53: 903-915

43 Menéndez N, Nur-e-Alam M, Fischer C, Braña AF, Salas JA, Rohr J, Méndez $C$. Deoxysugar transfer during chromomycin $\mathrm{A}_{3}$ biosynthesis in Streptomyces griseus subsp. griseus: new derivatives with antitumor activity. Appl Environ Microbiol 2006; 72: 67-77

44 García B, González-Sabín J, Menéndez N, Braña AF, Núñez LE, Morís F, Salas JA, Méndez C. The chromomycin CmmA acetyltransferase: a membrane-bound enzyme as a tool for increasing structural diversity of the antitumour mithramycin. Microb Biotechnol 2011; 4: 226-238

45 González-Sabín J, Morán-Ramallal R, Rebolledo F. Regioselective enzymatic acylation of complex natural products: expanding molecular diversity. Chem Soc Rev 2011; 40: 5321-5335
46 González-Sabín J, Núñez LE, Braña AF, Méndez C, Salas JA, Gotor V, Morís $F$. Regioselective enzymatic acylation of aureolic acids to obtain novel analogues with improved antitumor activity. Adv Synth Catal 2012; 354: $1500-1508$

47 Tevyashova AN, Zbarsky EN, Balzarini J, Shtil AA, Dezhenkova LG, Bukhman VM, Zbarsky VB, Preobrazhenskaya MN. Modification of the antibiotic olivomycin I at the 2'-keto group of the side chain. Novel derivatives, antitumor and topoisomerase I-poisoning activity. J Antibiot (Tokyo) 2009; 62: 37-41

48 Tevyashova AN, Olsufyeva EN, Turchin KF, Balzarini J, Bykov EE, Dezhenkova LG, Shtil AA, Preobrazhenskaya MN. Reaction of the antitumor antibiotic olivomycin I with aryl diazonium salts. Synthesis, cytotoxic and antiretroviral potency of 5-aryldiazenyl-6-0-deglycosyl derivatives of olivomycin I. Bioorg Med Chem 2009; 17: 4961-4967

49 Tevyashova AN, Shtil AA, Olsufyeva EN, Luzikov YN, Reznikova MI, Dezhenkova LG, Isakova EB, Bukhman VM, Durandin NA, Vinogradov AM, Kuzmin VA, Preobrazhenskaya MN. Modification of olivomycin A at the side chain of the aglycon yields the derivative with perspective antitumor characteristics. Bioorg Med Chem 2011; 19: 7387-7393

50 Scott D, Chen JM, Bae Y, Rohr J. Semi-synthetic mithramycin SA derivatives with improved anticancer activity. Chem Biol Drug Des 2013; 81: 615-624

51 Remsing LL, Bahadori HR, Carbone GM, McGuffie EM, Catapano CV, Rohr $J$. Inhibition of c-src transcription by mithramycin: structure-activity relationships of biosynthetically produced mithramycin analogues using the c-src promoter as target. Biochemistry 2003; 42: 8313-8324

52 Bataller M, Méndez C, Salas JA, Portugal J. Mithramycin SK modulates polyploidy and cell death in colon carcinoma cells. Mol Cancer Ther 2008; 7: 2988-2997

53 Bataller M, Méndez C, Salas JA, Portugal J. Cellular response and activation of apoptosis by mithramycin SK in p21(WAF1)-deficient HCT116 human colon carcinoma cells. Cancer Lett 2010; 292: 80-90

54 Barceló F, Scotta C, Ortiz-Lombardía M, Méndez C, Salas JA, Portugal J. Entropically-driven binding of mithramycin in the minor groove of $\mathrm{C}$ / G-rich DNA sequences. Nucleic Acids Res 2007; 35: 2215-2226

55 Barceló F, Ortiz-Lombardía M, Martorell M, Oliver M, Méndez C, Salas JA, Portugal J. DNA binding characteristics of mithramycin and chromomycin analogues obtained by combinatorial biosynthesis. Biochemistry 2010; 49: 10543-10552

56 Mansilla S, Garcia-Ferrer I, Méndez C, Salas JA, Portugal J. Differential inhibition of restriction enzyme cleavage by chromophore-modified analogues of the antitumour antibiotics mithramycin and chromomycin reveals structure-activity relationships. Biochem Pharmacol 2010; 79: $1418-1427$

57 Previdi S, Malek A, Albertini V, Riva C, Capella C, Broggini M, Carbone GM, Rohr J, Catapano CV. Inhibition of Sp1-dependent transcription and antitumor activity of the new aureolic acid analogues mithramycin SDK and SK in human ovarian cancer xenografts. Gynecol Oncol 2010; 118: $182-188$

58 Malek A, Núñez LE, Magistri M, Brambilla L, Jovic S, Carbone GM, Morís F, Catapano CV. Modulation of the activity of Sp transcription factors by mithramycin analogues as a new strategy for treatment of metastatic prostate cancer. PLoS One 2012; 7: e35130

59 Roth J, Peer CJ, Widemann B, Cole DE, Ershler R, Helman L, Schrump D, Figg WD. Quantitative determination of mithramycin in human plasma by a novel, sensitive ultra-HPLC-MS/MS method for clinical pharmacokinetic application. J Chromatogr B Analyt Technol Biomed Life Sci 2014; 970: 95-101

60 Vizcaíno C, Mansilla S, Núñez LE, Méndez C, Salas JA, Morís F, Portugal J. Novel mithramycins abrogate the involvement of protein factors in the transcription of cell cycle control genes. Biochem Pharmacol 2012; 84: 1133-1142

61 Grohar PJ, Helman LJ. Prospects and challenges for the development of new therapies for Ewing sarcoma. Pharmacol Ther 2013; 137: 216-224

62 Fernández-Guizán A, Mansilla S, Barceló F, Vizcaíno C, Núñez LE, Morís F, González S, Portugal J. The activity of a novel mithramycin analog is related to its binding to DNA, cellular accumulation, and inhibition of Sp1-driven gene transcription. Chem Biol Interact 2014; 219: 123-132

63 Vizcaíno C, Núñez LE, Morís F, Portugal J. Genome-wide modulation of gene transcription in ovarian carcinoma cells by a new mithramycin analogue. PLoS One 2014; 9: e104687 